\title{
Evaluation of Beijing Air Quality Based on the Judgment Matrix
}

\author{
Cheng Ming
}

\author{
Department of English, North China Electricity Power University, Baoding, 071000, China \\ email: 442867007@qq.com
}

Keywords: air quality, $\mathrm{PM}_{2.5}$, evaluation, AHP

\begin{abstract}
With the quick advancement of the economy and industrialization, human beings have emitted a huge amount of pollutants, so the air contamination gets worse that largely influences the human health, ecological balance and social development. Air pollution, therefore, has become a focus all over the country. In order to study the serious problems like the sources and transformation of air pollutants, the paper included the statistics of Beijing air quality in the November and December of 2016. The goal was to build the air quality assessment model of Beijing in a more scientific, objective and reasonable way.
\end{abstract}

\section{Introduction}

The atmosphere is an essential environment that all of the creatures on the earth depend upon. However, with quick development of the economy, industrialization springs up over the past decades, leading to the growing kinds of air pollutants, destroying atmospheric environment and aggravating smog, which largely impacts on human health, plants, animals and ecological environment. Particularly after winter, air quality has widely become a heated topic, the forecast and monitoring result of it usually being criticized. Environmental Protection Department devotes to environmental pollution control, yet the effect is barely measurable. Hence, it's significant to evaluate and predict the atmospheric pollutants, making people realize the severity of environment contamination and start from oneself to protect our living environment.

Among the air pollutants, $\mathrm{PM}_{2.5}, \mathrm{PM}_{10}, \mathrm{SO}_{2}$ and $\mathrm{NO}_{2}$ rank the top of the list. $\mathrm{PM}_{2.5}$ is the particulate matter with a diameter of 2.5 micrometers or less. Although it is only a small part of the atmospheric composition, it has a strong influence on air quality as well as visibility. Tiny in size, $\mathrm{PM}_{2.5}$ has quantities of poisonous and harmful substances, and can suspend in the air for a long time and transmit over long distances. Once it is inhaled into human body, it will a great harm [1]. $\mathrm{PM}_{10}$ is correctly defined as particulate matter with a mean aerodynamic diameter of $10 \mu \mathrm{m}$, including $\mathrm{PM}_{2.5}$. The long exposure to $\mathrm{PM}_{10}$ that have been widely studied in humans and animals include cough, asthma, lung cancer, cardiovascular disease and respiratory diseases.

Therefore, it's necessary to reasonably estimate the pollution index in the atmosphere.

\section{Air Quality Assessment Model}

Original Model Analysis. At present, One-Dimensional Interpolation Algorithm in China is adopted to calculate Air Quality Index (AQI) shown as Table 1. The one hour average concentration limit of $\mathrm{SO}_{2}, \mathrm{NO}_{2}$, $\mathrm{CO}$ is only used for real-time reporting. In the daily newspaper 24 hour average concentration limit is used for the corresponding pollutant. The average concentration limit of $\mathrm{SO}_{2}$ is higher than $800 \mathrm{ug} / \mathrm{m}^{3}$, and its air quality index is not calculated. $\mathrm{O}_{3} 8$ hour average concentration limit is higher than $800 \mathrm{ug} / \mathrm{m}^{3}$, no longer its air quality index is not calculated. $\mathrm{O}_{3}$ air quality index by one hour average concentration of the sub index report.

For pollutant project concentration, we can use the equation:

$$
I A Q I_{P}=\frac{I A Q I_{H i}-I A Q I_{L o}}{B P_{H i}-B P_{L o}}\left(C_{P}-B P_{L o}\right)+I A Q I_{L o}
$$

Then IAQI of all pollutants are calculated in turn, and finally the equation is used to reckon AQI.

$$
A Q I=\max _{10}\left[I A Q I_{1}, I A Q I_{2}, \ldots, I A Q I_{n}\right\}
$$


Table 1 IAQI and relevant pollutant concentration limits [2]

\begin{tabular}{|c|c|c|c|c|c|c|}
\hline \multicolumn{7}{|c|}{ Air quality index and corresponding pollutant concentration } \\
\hline IAQI & $\mathrm{SO}_{2}\left(\mathrm{ug} / \mathrm{m}^{3}\right)$ & $\mathrm{NO}_{2}\left(\mathrm{ug} / \mathrm{m}^{3}\right)$ & $\mathrm{PM}_{10}\left(\mathrm{ug} / \mathrm{m}^{3}\right)$ & $\mathrm{CO}\left(\mathrm{mg} / \mathrm{m}^{3}\right)$ & $\mathrm{O}_{3}\left(\mathrm{ug} / \mathrm{m}^{3}\right)$ & $\mathrm{PM}_{2.5}\left(\mathrm{ug} / \mathrm{m}^{3}\right)$ \\
\hline 0 & 0 & 0 & 0 & 0 & 0 & 0 \\
\hline 50 & 150 & 100 & 50 & 5 & 160 & 35 \\
\hline 100 & 500 & 200 & 150 & 10 & 200 & 75 \\
\hline 150 & 650 & 700 & 250 & 35 & 300 & 115 \\
\hline 200 & 800 & 1200 & 350 & 60 & 400 & 150 \\
\hline 300 & (2) & 2340 & 420 & 90 & 800 & 250 \\
\hline 400 & (2) & 3090 & 500 & 120 & 1000 & 350 \\
\hline 500 & (2) & 3840 & 600 & 150 & 1200 & 500 \\
\hline
\end{tabular}

It is not hard to discover from the real-time air-monitoring data that, compared with other pollutants, $\mathrm{PM}_{2.5}$ and $\mathrm{PM}_{10}$ have lager IAQI values. That is, the value of AQI is mainly determined by the IAQI of $\mathrm{PM}_{2.5}$ and PM10, while other pollutants are not involved or partly involved in the calculation of AQI, so that we neglect the AQI of other pollutants like $\mathrm{SO}_{2}$ and are incapable of exactly reflecting the real situation of air quality.

To evaluate air quality in a more exact and reasonable way, therefore, we keep using One-Dimensional Interpolation Algorithm and adopt Analytic Hierarchy Process to build a new model, which is used for the calculation of AQI.

Modeling Analysis. The Harm of Air Pollutants to Human Health. Particulate matters or PM, is the term for particles found in the air, including dust, dirt, soot, smoke, and liquid droplets. $\mathrm{PM}_{2.5}$ particles are air pollutants with a diameter of 2.5 micrometers or less, small enough to invade even the smallest airways. Particles less than 10 micrometers in diameter $\left(\mathrm{PM}_{10}\right)$ pose a health concern because they can be inhaled into and accumulate in the respiratory system. Particles less than 2.5 micrometers in diameter $\left(\mathrm{PM}_{2.5}\right)$ are referred to as "fine" particles and are believed to pose the greatest health risks. Because of their small size (approximately 1/30th the average width of a human hair), fine particles can lodge deeply into the lungs [3].

Sulfur dioxide is a major air pollutant and has significant impacts upon human health. In addition, the concentration of sulfur dioxide in the atmosphere can influence the habitat suitability for plant communities, as well as animal life. Sulfur dioxide emissions are a precursor to acid rain and atmospheric particulates [4].

Nitrogen oxide (also known as $\mathrm{NO}_{x}$, such as $\mathrm{NO}, \mathrm{NO}_{2}$ and $\mathrm{NO}_{3}$ ) reacts with ammonia, moisture, and other compounds to form nitric acid vapor and related particles. Small particles can penetrate deeply into sensitive lung tissue and damage it, causing premature death in extreme cases. Inhalation of such particles may cause or worsen respiratory diseases, such as emphysema or bronchitis, or may also aggravate existing heart disease [5].

Low levels of carbon monoxide produce symptoms such as mild headaches, nausea and shortness of breath. Long-term exposure to mild levels of carbon monoxide can cause complications over time. Moderate exposure to carbon monoxide exhibits a wide variety of identifiable symptoms in the person affected. At this level of exposure, the headaches can become severe, dizziness and mental confusion may occur as well. A person exposed to moderate levels of carbon monoxide may even faint [6].

Photochemical oxidants (like ozone) absorbs most of the sun's ultraviolet radiation is released, so that harm plants and animals from such rays. Low concentrations of ozone can be disinfected, but excessive ozone is an invisible killer. It strongly stimulates the respiratory tract, causing sore throat, coughing, chest tightness, causing bronchitis and emphysema. Ozone can cause nervous intoxication, dizziness, headache, decreased visual acuity, memory loss; Ozone harmful to human skin damaging effects of vitamin E play, resulting in human skin wrinkling, dark spots; Ozone will damage the body's immune function, induce chromosome disease, accelerated aging, resulting in pregnant women born deformed children [7]. 
According to the studies available, there exists a huge difference between the effects of various air pollutants on human body, Toxicant mechanism and mode of action. Hence, when we evaluate air quality, every kind of pollutant needs to account for a different weight, instead of taking the maximum of IAQI values as the final one.

Construct Judgment Matrix. Based on the above analysis, we can adopt Analytic Hierarchy Process to construct Judgment Matrix so as to calculate the proportion of all pollutants sub-index $\beta_{1}$, $\beta_{2}, \beta_{3}, \beta_{4}, \beta_{5}, \beta_{6}$, so:

$$
\mathrm{AQI}=\beta_{1} \mathrm{IAQI}_{1}+\beta_{2} \mathrm{IAQI}_{2}+\beta_{3} \mathrm{IAQI}_{3}+\beta_{4} \mathrm{IAQI}_{4}+\beta_{5} \mathrm{IAQI}_{5}+\beta_{6} \mathrm{IAQI}_{6}
$$

Definition: $w_{\mathrm{ij}}$ represents the ratio of $x_{\mathrm{i}}, y_{\mathrm{i}}$ and the influence on the upper layer $A$. The following Table 2 illustrates the definition of all scales.

Table 2 Definition of All Scales

\begin{tabular}{c|l}
\hline Scale & \multicolumn{1}{c}{ Definition } \\
\hline$w_{\mathrm{ij}}=1$ & $\begin{array}{l}\text { Represents the comparison of } x_{\mathrm{i}} \text { and } y_{\mathrm{i}} \text { that shows the same importance on } \\
\text { the upper layer } A(\text { equal) }\end{array}$ \\
\hline$w_{\mathrm{ij}}=3$ & $\begin{array}{l}\text { Represents the comparison of } x_{\mathrm{i}} \text { and } y_{\mathrm{i}} \text { that shows a little lager importance } \\
\text { on the upper layer } A \text { (slightly strong) }\end{array}$ \\
\hline$w_{\mathrm{ij}}=5$ & $\begin{array}{l}\text { Represents the comparison of } x_{\mathrm{i}} \text { and } y_{\mathrm{i}} \text { that shows the lager importance on } \\
\text { the upper layer } A \text { (strong) }\end{array}$ \\
\hline$w_{\mathrm{ij}}=7$ & $\begin{array}{l}\text { Represents the comparison of } x_{\mathrm{i}} \text { and } y_{\mathrm{i}} \text { that shows much lager importance on } \\
\text { the upper layer } A(\text { very strong) }\end{array}$ \\
\hline$w_{\mathrm{ij}}=9$ & $\begin{array}{l}\text { Represents the comparison of } x_{\mathrm{i}} \text { and } y_{\mathrm{i}} \text { that shows extremely lager } \\
\text { importance on the upper layer } A(\text { absolutely strong) }\end{array}$ \\
\hline$w_{\mathrm{ij}}=2,4,6,8$ & $\begin{array}{l}\text { Represents the comparison of } x_{\mathrm{i}} \text { and } y_{\mathrm{i}} \text { that shows the importance on the } \\
\text { upper layer } A \text { between the two above }\end{array}$ \\
\hline
\end{tabular}

According to Table 2, the following Table 3 show the importance of two air pollutants by comparison and analysis.

Table 3 Results of Air Pollutant's Comparison

\begin{tabular}{ccccccc}
\hline & $\mathrm{PM}_{2.5}$ & $\mathrm{PM}_{10}$ & $\mathrm{SO}_{2}$ & $\mathrm{NO}_{2}$ & $\mathrm{CO}$ & $\mathrm{O}_{3}$ \\
\hline $\mathrm{PM}_{2.5}$ & 1 & 1 & $7 / 5$ & $7 / 3$ & 7 & 7 \\
$\mathrm{PM}_{10}$ & 1 & 1 & $7 / 5$ & $7 / 3$ & 7 & 7 \\
$\mathrm{SO}_{2}$ & $5 / 7$ & $5 / 7$ & 1 & $5 / 3$ & 5 & 5 \\
$\mathrm{NO}_{2}$ & $3 / 7$ & $3 / 7$ & $3 / 5$ & 1 & 3 & 3 \\
$\mathrm{CO}$ & $1 / 7$ & $1 / 7$ & $1 / 5$ & $1 / 3$ & 1 & 1 \\
$\mathrm{O}_{3}$ & $1 / 7$ & $1 / 7$ & $1 / 5$ & $1 / 3$ & 1 & 1 \\
\hline
\end{tabular}

So the Judgment Matrix is:

$$
W=\left[\begin{array}{llllll}
1 & 1 & \frac{7}{5} & \frac{7}{3} & 7 & 7 \\
1 & 1 & \frac{7}{5} & \frac{7}{3} & 7 & 7 \\
\frac{5}{7} & \frac{5}{7} & 1 & \frac{5}{3} & 5 & 5 \\
\frac{3}{7} & \frac{3}{7} & \frac{3}{5} & 1 & 3 & 3 \\
\frac{1}{7} & \frac{1}{7} & \frac{1}{5} & \frac{1}{3} & 1 & 1 \\
\frac{1}{7} & \frac{1}{7} & \frac{1}{5} & \frac{1}{3} & 1 & 1
\end{array}\right]
$$


So the eigenvector and eigenvalue of matrix $W$ are:

$$
\boldsymbol{a}=[0.2917,0.2917,0.2083,0.1250,0.0417,0.0417]^{\mathrm{T}}, \lambda=6
$$

So $\beta_{1}=0.2917, \beta_{2}=0.2917, \beta_{3}=0.2083, \beta_{4}=0.1250, \beta_{5}=0.0417, \beta_{6}=0.0417$

\section{Test Results}

Calculate Consistency Index of Judgment Matrix:

$$
C I=\frac{\lambda_{\max }-n}{n-1}=0
$$

Calculate Consistency Ratio of Judgment Matrix:

$$
C R=\frac{C I}{R I}=0<0.10
$$

Since $C R<0.10$, the consistency of Judgment Matrix W can be accepted and the model meets the requirements as shown in Table4.

Table 4 Final results

\begin{tabular}{ccccccc}
\hline Pollutant & $\mathrm{PM}_{2.5}$ & $\mathrm{PM}_{10}$ & $\mathrm{SO}_{2}$ & $\mathrm{NO}_{2}$ & $\mathrm{CO}$ & $\mathrm{O}_{3}$ \\
\hline Ratio & 0.2917 & 0.2917 & 0.2083 & 0.1250 & 0.0417 & 0.0417 \\
\hline
\end{tabular}

So the new AQI equation is:

$$
\mathrm{AQI}=0.2917 \mathrm{IAQI}_{1}+0.2917 \mathrm{IAQI}_{2}+0.2083 \mathrm{IAQI}_{3}+0.1250 \mathrm{IAQI}_{4}+0.0417 \mathrm{IAQI}_{5}+0.0417 \mathrm{I} \mathrm{AQI}_{6}
$$

\section{Conclusion}

The paper utilized the statistics of Beijing air quality in certain days of January and built the air quality evaluation model by AHP, according to the influence of air pollutants upon human body and air quality. The specific ratios of various pollutants were deprived: inhalable particulate matter shows the biggest effect on the air quality, $\mathrm{SO}_{2}$ and $\mathrm{NO}_{2}$ after it, and $\mathrm{CO}$ and $\mathrm{O}_{3}$ the smallest.

Compared with the original model, the model in the paper is more objective, exact and reliable, though it didn't take into consideration the relationship among various air pollutants and other elements' impacts on air quality.

\section{References}

[1] "7 million premature deaths annually linked to air pollution". WHO. 25 March 2014. Retrieved 25 March 2014.

[2] https://en.wikipedia.org/wiki/Air_quality_index

[3] Particulate Matter | Air \& Radiation | US EPA

[4] https://en.wikipedia.org/wiki/Sulfur_dioxide

[5] https://en.wikipedia.org/wiki/Nitrogen_oxide

[6] Wu, L; Wang, R (December 2005). "Carbon Monoxide: Endogenous Production, Physiological Functions, and Pharmacological Applications". Pharmacol Rev. 57 (4): 585-630. doi:10.1124/pr.57.4.3.PMID 16382109

[7] Weinhold B (2008). "Ozone nation: EPA standard panned by the people". Environ. Health Perspect. 116 (7): A302-A305.doi:10.1289/ehp.116-a302. PMC 2453178. PMID 18629332. 